\title{
MAGNETIC EVALUATION OF THE STRUCTURAL AND PHASE CHANGES IN INDIVIDUAL LAYERS OF MULTILAYER PRODUCTS
}

\author{
E. S. Gorkunov ${ }^{1 *}$ \\ ${ }^{1}$ Institute of Engineering Science, Ural Branch of the Russian Academy of Sciences, \\ 34 Komsomolskaya St., Ekaterinburg, Russian Federation \\ *Corresponding author. E-mail: ges@imach.uran.ru; \\ address for correspondence: 34 Komsomolskaya St., Ekaterinburg, Russian Federation. \\ Tel.: +7 (343) 37447 25; fax: +7 (343) 3745330
}

Magnetic hysteresis loop distortion occurring during the magnetization reversal of multilayer ferromagnets can be used to evaluate the structural changes and phase transformations in composite product layers with different properties. For practical application, it is proposed either to record the differential magnetic permeability of each layer or to measure the electromotive force in the coil encompassing a product under magnetization reversal by linear alternating current.

Keywords: composite material, surface hardening, structure, phase, hysteresis loop, differential magnetic permeability, field of differential magnetic permeability, coercive force.

DOI: $10.17804 / 2410-9908.2017 .2 .006-027$

\section{References}

1. Potapov I.N., Lebedev V.N., Kobelev A.G., Kuznetsov E.V., Bykov A.A., Kluchnikov R.M. Sloistye metallicheskie kompositsii [Laminated Metal Composites]. M., Metallurgiya Publ., 1986, 216 p. (In Russian).

2. Lakhtin Yu.M., Leontieva V.P. Materialovedenie [Material Science]. M., Mashinostroenie Publ., 1990, 528 p. (In Russian).

3. Gorkunov E.S., Lapidus B.M., Zagainov A.V., Voronov S.A., Bushmeleva G. Y. Application of differential magnetic permeability in the quality control of surface hardening. Soviet Journal of Nondestructive Testing-USSR, 1988, vol. 24, no. 7, pp. 441-446.

4. Gorkunov E.S., Lapidus B.M. Magnetic properties of double-layer ferromagnets as applied to quality control of surface-hardened products. In: Strukturno-fazovye prevrashcheniya v metallakh: problemy prochnosti i plastichnosti [Structural-Phase Transitions in Metals: Strength and Plasticity Problems]. Sverdlovsk, UNTs AN SSSR Publ., 1987, pp. 103-110. (In Russian).

5. Gorkunov E.S Magnetic Methods and Instruments for the Quality-Control of the CaseHardening of Ferromagnetic Steel Objects - (Review). Soviet Journal of Nondestructive TestingUSSR, 1991, vol. 27, no. 1, pp. 1-18.

6. Gorkunov E.S., Lapidus B.M., Zagainov A.B. A method for quality control of multilayer ferromagnetic products. Avtorskoe svidetelstvo no. 1252718 [RF Patent], bul. izobr. no. 31, 1986, p. 182. (In Russian).

7. Shcherbinin V.E., Gorkunov E.S. Magnitnyi control kachestva metallov [Magnetic Quality Control of Metals]. Ekaterinburg, UrO RAN, 1996, 264 p. ISBN 5-7691-0655-7. (In Russian).

8. Dekhtyar V.M., Gorbunova A.M., Baldina L.M., Kasatkina G.M. Magnetic Determination of the Depth of a Hardened Layer. Zavodskaya laboratoriya, 1946, vol. 12, no. 9-10, pp. 808-816. (In Russian).

9. Dekhtyar V.M. On the coercive force of a two-layer cylinder. ZhETF, 1946, iss. 10, pp. 2-7. (In Russian).

10. Mikheev M.N., Gorkunov E.S. Magnitnye metody strukturnogo analiza [Magnetic Methods for Structural Analysis and Nondestructive Testing]. M., Nauka Publ., 1993. 252 p. 
11. Kifer I.I., Semenovskaya I.B., Fomin I.N. On the relation between differential permeability and coercive force. Zavodskaya laboratoriya, 1969, no. 10, pp. 1191-1193. (In Russian).

12. Brinksmeier K., Scheider E., Theiner W.A., Tönsholff H.K. Non-destructive testing for evaluating integrity. Annals of the CIRP, 1984, vol. 33, no. 2, pp. 489-509.

13. Gorkunov E.S., Mitropolskaya S.Yu., Groznaya E.M., Mushnikov A.N., Osintseva A.L., Tueva E.A. Effect of Elasto-Plastic Loading on the Magnetic Characteristics of Steel 20 Hardened with Gas Case-Hardening. Russian Journal of Nondestructive Testing, 2011, vol. 47, no. 4, pp. 221-231. DOI: $10.1134 / \mathrm{S} 106183091104005 X$.

14. Ryzhov N.M., Fakhurtdinov R.S., Smirnov A.E. Cyclic Strength of Steel 16kh3nvfbm-Sh (Vks-5) after Vacuum Carburizing. Metal Science and Heat Treatment, 2010, vol. 52, nos. 1-2, pp. 61-66. DOI: 10.1007/s11041-010-9230-9.

15. Borisenok G.V., Vasiliev L.A., Voroshnin L.G. Khimiko-termicheskaya obrabotka metallov $i$ splavov [Chemical and Heat Treatment of Metals and Alloys]. M., Metallurgiya Publ., 1981, pp. 424. (In Russian).

16. Gorkunov E.S., Mitropol'skaya S.Yu., Zadvorkin S.M., Osintseva A.L., Vichuzhanin D.I. Effect of Laser Surface Hardening on Magnetic Characteristics of a Carbon Steel under Loading. Russian Journal of Nondestructive Testing, 2008, vol. 44, no. 8, pp. 560-565. DOI: $10.1134 / \mathrm{S} 1061830908080081$.

17. Gorkunov E.S., Mitropolskaya S.Yu., Osintseva A.L., Vichuzhanin D.I. Magnetic investigation of strains and stresses in surface-hardened materials. Physical Mesomechanics, 2009, vol. 12, iss. 3-4, pp. 190-198. DOI: 10.1016/j.physme.2009.07.012.

18. Gorkunov E.S., Povolotskaya A.M., Tueva E.A., Goruleva L.S., Zadvorkin S.M. Determination of the Magnetic Properties of Separate Zones of Welds and the Width of Welded Joints Based on Magnetic Measurements. Russian Journal of Nondestructive Testing, 2011, vol. 47, no. 9, pp. 577-586. DOI: 10.1134/S1061830911090038.

19. Gorkunov E.S., Zadvorkin S.M., Emel'yanov I.G., Mitropol'skaya S.Yu. Variation of Magnetic Properties of Two-Layer Carbon-Steel Products under Tension. The Physics of Metals and Metallography, 2007, vol. 103, no. 6, pp. 624-632. DOI: 10.1134/S0031918X07060129.

20. Gorkunov E.S., Povolotskaya A.M., Kuleev V.G., Chistyakov V.K., Korobka O.B. Coercive Force of a Package of Steel Sheets with Diff erent Degrees of Magnetic Hardness. Russian Journal of Nondestructive Testing, 2002, vol. 38, no. 5, pp. 331-338. DOI: 10.1023/A:1020960918166.

21. Gorkunov E.S., Emelyanov I.G., Zadvorkin S.M., Mitropolskaya S.Yu. A model of the stressstate state of a two-layer steel product under uniaxial tension. Metally, 2007, no. 1, pp. 78-82. (In Russian).

22. Goldshtein M.I., Grachev S.V., Veksler Yu.G. Spetsialnye stali [Special Steels], M., MISIS Publ., 1999, 408 p. (In Russian).

23. Filippov M.A., Litvinov V.S., Nemirovskiy Y.R. Stali s metastabilnym austenitom [Steels with metastable austenite]. M., Metallurgiya, 1988, 255 p.

24. Gorkunov E.S., Zadvorkin S.M., Putilova E.A., Povolotskaya A.M., Goruleva L.S., Veretennikova I.A., Kamantsev I.S. The Application of Magnetic Structural Phase Analysis for the Diagnostics of the State of a 08X18H10T Steel-C 3 Steel Composite Material and Its Components That Were Subjected to Plastic Deformation. Russian Journal of Nondestructive Testing, 2012, vol. 48, no. 6, pp. 346-356. DOI: 10.1134/S1061830912060022.

25. Gorkunov E.S., Zadvorkin S.M., Putilova E.A. Magnetic estimation of stresses applied to a two-layer steel C(T)3-steel 08X18H10T composite material during elastoplastic deformation by uniaxial tension. Russian Journal of Nondestructive Testing, 2012, vol. 48, no. 8, pp. 495-504. DOI: $10.1134 / \mathrm{S} 1061830912080050$. 
Подана в журнал: 28.04.2017

УДК 620.179.14.662.223.662.09

DOI: $10.17804 / 2410-9908.2017 .2 .006-027$

\title{
МАГНИТНЫЕ МЕТОДЫ ОЦЕНКИ СТРУКТУРНЫХ И ФАЗОВЫХ ИЗМЕНЕНИЙ В ОТДЕЛЬНЫХ СЛОЯХ МНОГОСЛОЙНЫХ ИЗДЕЛИЙ
}

\author{
Э. С. Горкунов ${ }^{1} *$ \\ ${ }^{1}$ Федеральное государственное бюджетное учреждение науки \\ Институт машиноведения Уральского отделения Российской академии наук, \\ ул. Комсомольская, 34, Екатеринбург, Российская Федерация \\ *Ответственный автор. Электронная почта: ges@imach.uran.ru; \\ адрес для переписки: ул. Комсомольская, 34, Екатеринбург, Российская Федерация. \\ Тел.: +7 (343) 374-47-25; факс: +7 (343) 374-53-30
}

Искажения петель магнитного гистерезиса при перемагничивании многослойных ферромагнетиков могут быть использованы для оценки структурных изменений и фазовых превращений, происходящих в отдельных слоях композиционных изделий с различающимися свойствами. Для практического использования предлагается, либо регистрировать дифференциальную магнитную проницаемость каждого из слоев, либо измерять электродвижущую силу в катушке, охватывающей изделие при его перемагничивании линейно меняющимся током.

Ключевые слова: композиционный материал, поверхностное упрочнение, структура, фаза, петля гистерезиса, дифференциальная магнитная проницаемость, поле максимальной дифференциальной магнитной проницаемости, коэричитивная сила

\section{1. Введение}

В современном машиностроении все шире используются многослойные композиционные материалы. Использование слоев различного функционального назначения существенно расширяет эксплуатационные характеристики композиционых материалов (КМ). При этом слои металлов, входящих в состав КМ, могут обладать существенным различием по структуpe, прочностным и физическим свойствам. [1]. Среди них детали с различными видами поверхностного упрочнения, сварные соединения, стальные канаты, свитые из проволоки разного типа, биметаллические, коаксиальные изделия и др. Для правильной эксплуатации и обеспечения диагностики подобных материалов очень важно знать закономерности изменения прочностных и физических свойств каждого из слоев при различных эксплуатационных воздействиях.

\section{2. Поверхностно-упрочненные изделия}

Простейшим примером использования в машиностроении двухслойных деталей являются поверхностно упрочненные изделия. Структура и свойства поверхностного слоя во многом определяют последующие эксплуатационные характеристики изделия в целом. В полной мере это относится к слоям, полученным методами закалки с помощью ТВЧ и цементации, которые придают поверхностному слою высокую твердость и износостойкость, повышают предел контактной выносливости и пределы выносливости при изгибе и кручении [2].

Проблему одновременного определения свойств как поверхностно упрочненного слоя, так и сердцевины изделия можно в некоторых случаях решить путем использования особенностей перемагничивания двухслойного ферромагнетика [3-10]. 
Петля гистерезиса двухслойного ферромагнетика имеет искаженный вид. На рис. 1 a показаны петли гистерезиса двух однородных материалов (кривые 1 и 2) и двухслойного образца (кривая 3), состоящего из этих материалов. Поскольку образцы представляли собой тороиды, имеющие одинаковые размеры, и перемагничивание происходило вдоль плоскости раздела слоев, кривая 3 может быть получена путем аддитивного сложения двух первых с учетом сечения каждого из слоев:

$$
B(H)=\frac{S_{1}}{S} B_{1}(H)+\frac{S_{2}}{S} B_{2}(H),
$$

где $B_{1}$ и $B_{2}$ - индукция первого и второго слоя; $B$ - средняя по сечению индукция двухслойного образца; $S$ - поперечное сечение двухслойного образца; $S_{1}$ и $S_{2}$ - поперечное сечение первого и второго слоев. Петли гистерезиса, рассчитанные по формуле (1) и определенные экспериментально, практически совпадали. Перегибы петли гистерезиса (рис. $1 a$, кривая 3), свидетельствуя о наличии второго слоя, отличного от основной массы материала, не характеризуют количественно ни его толщину, ни его свойства. Коэрцитивная сила $H_{\mathrm{c}}$ такого ферромагнетика во многом будет определяться формой петли гистерезиса каждого из слоев. Физическое состояние двухслойного ферромагнетика в момент определения коэрцитивной силы отличается от однородного тем, что магнитные потоки в каждом из слоев отличаются от нуля, равны и противоположно направлены, а поэтому компенсируют друг друга [9].

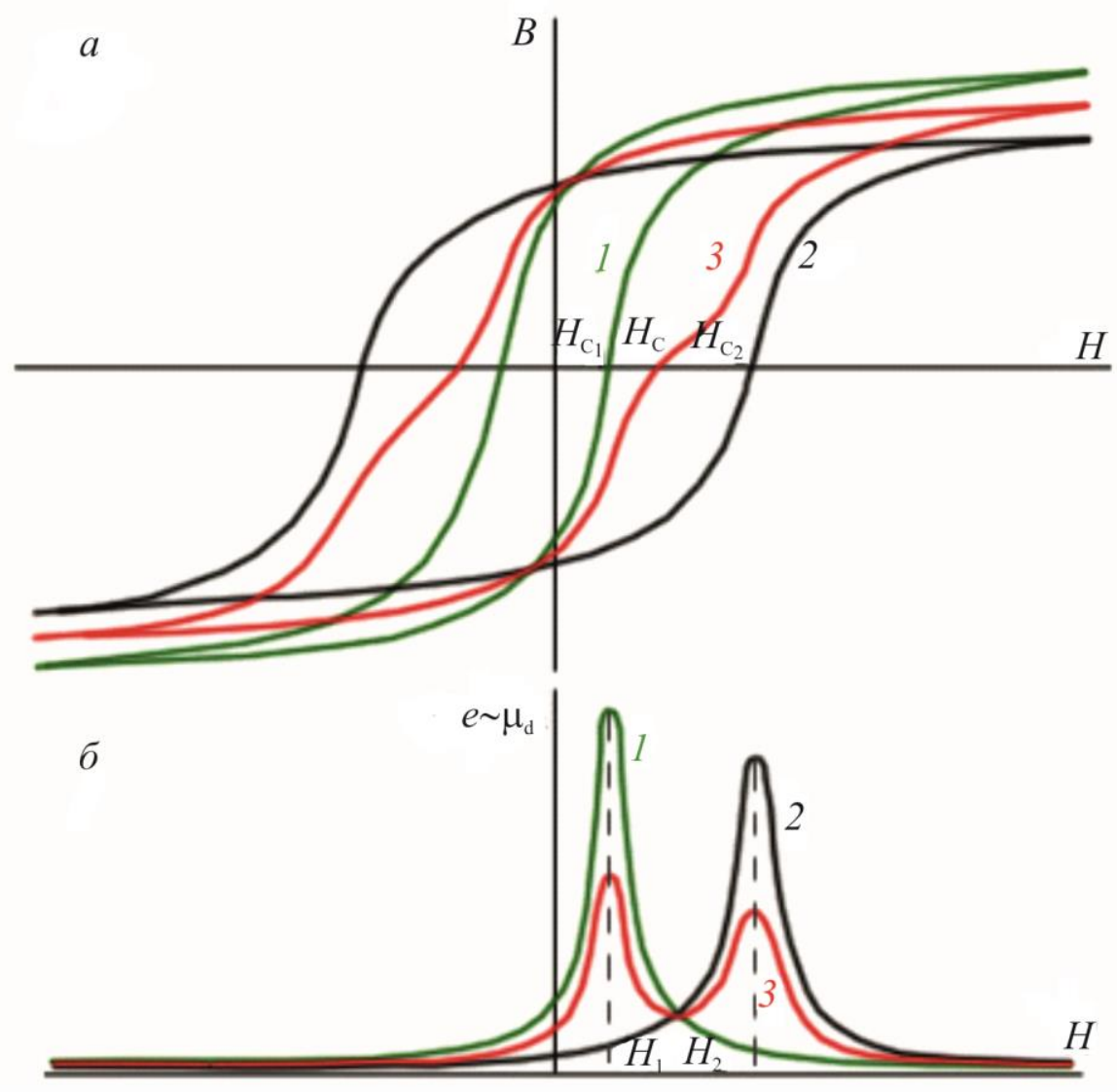

Рис. 1. Петли магнитного гистерезиса ( $a$ ) и соответствующая им ЭДС, пропорциональные дифференциальным проницаемостям (б) однородных тороидов $(1,2)$ и двухслойного тороида (3) 
Более информативна зависимость дифференциальной магнитной проницаемости $\mu_{\mathrm{d}}$ от напряженности перемагничивающего поля $H$. Наиболее простым способом получения зависимостей $\mu_{\mathrm{d}}(H)$ и определения полей $H_{1}$ и $H_{2}$, при которых происходит образование перегибов, является измерение ЭДС катушки, охватывающей образец при его перемагничивании линейно изменяющимся током. При этом

$$
e=-\omega \frac{d \Phi}{d t}=-\omega \frac{d \Phi}{d H} \frac{d H}{d t}=-\omega \frac{d H}{d t}\left(\frac{d \Phi_{1}}{d H}+\frac{d \Phi_{2}}{d H}\right) \cong-\omega \frac{d H}{d t}\left(S_{1} \mu_{d_{1}}+S_{2} \mu_{d_{2}}\right),
$$

где $\Phi, \Phi_{1}, \Phi_{2}-$ магнитные потоки в двухслойном образце и в каждом из слоев соответственно. Если обеспечить в процессе измерения $\mathrm{d} H / \mathrm{d} t=$ const, то

$$
e=k\left(\mathrm{~S}_{1} \mu_{d_{1}}+\mathrm{S}_{2} \mu_{d_{2}}\right)
$$

И если слои однородны по своему сечению, то

$$
h \mu_{\mathrm{d}}=h_{1} \mu_{\mathrm{d}_{1}}+h_{2} \mu_{\mathrm{d}_{2}}
$$

где $h_{1}$ и $h_{2}$ - относительные толщины каждого из слоев. Как правило, проницаемость магнитожесткого упрочненного слоя мала в поле, при котором проницаемость магнитомягкого слоя достигает своего максимума, и наоборот, т. е. дифференциальная магнитная проницаемость в поле $H_{\mu_{\mathrm{d} 1}}$ будет определяться произведением $h_{1} \mu_{\mathrm{d}_{1}}$, а в поле $H_{\mu_{\mathrm{d}_{2}}} h_{2} \mu_{\mathrm{d}_{2}}$. Известно [11], что поле максимальной дифференциальной проницаемости образца практически совпадает со значением его коэрцитивной силы. Таким образом, определяя значения $H_{1}$ и $H_{2}$ по местоположению максимумов $е$ на кривой $e(H)$ (рис. 1 б) для двухслойного образца, можно получить информацию о величине коэрцитивной силы $[3,11]$ и, следовательно, о физико-механических свойствах каждого из слоев, а по известным закономерностям $e \approx \mu_{\mathrm{d}_{\max }}$ определить толщину этих слоев. Аналогичные максимумы наблюдали при изучении скачков Баркгаузена в двухслойных ферромагнетиках [12].

Дифференциальная магнитная проницаемость, определенная при линейно изменяющемся во времени поле путем измерения ЭДС измерительной обмотки [3], для серии образцов с различными толщинами закаленного слоя и сердцевины представлена на рис. $2 a$. Видно, что максимумы $\mu_{\mathrm{d}}$ наблюдаются примерно в одном и том же поле для образцов с различным соотношением слоев и с одинаковыми от образца к образцу свойствами этих слоев. На рис. 26 приведены зависимости для однородных и двухслойных образцов. Слои последних изготовлены из тех же материалов, что и однородные образцы. Из рис. 2 следует, что поля максимальной дифференциальной проницаемости однородных материалов соответствуют аналогичным полям двухслойных образцов, изготовленных из тех же материалов.

Выше говорилось о двухслойном ферромагнетике, хотя на практике поверхностно упрочненное изделие всегда имеет переходную зону с плавно меняющимися от поверхности к глубине свойствами. Исследования на образцах, вырезанных из поверхностно закаленных токами высокой частоты деталей полуоси автомобиля из стали 40X, показали, что присутствие переходной зоны существенно не меняет характер кривой. 

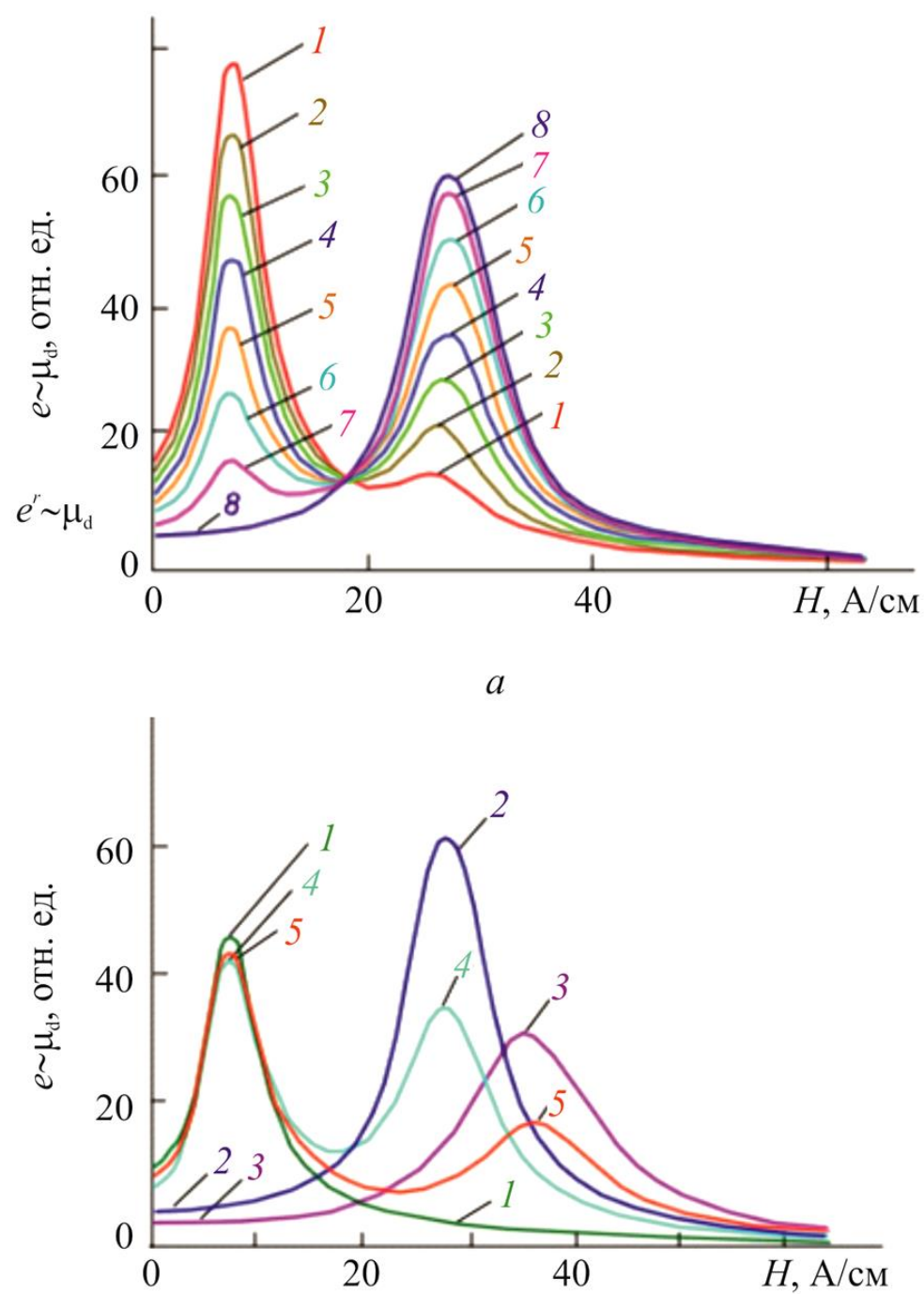

б

Рис. 2. Зависимости $\mu_{\mathrm{d}}(H)$ для однородных и двухслойных тороидов:

$a$ - с различным содержанием магнитомягкого и магнитожесткого слоев: 1 - толщина магнитомягкого слоя 7 мм, магнитожесткого 1 мм; 2 - 6 и 2 мм; 3 - 5 и 3 мм; 4 - 4 и 4 мм; $5-3$ и 5 мм; $6-2$ и 6 мм; $7-1$ и 7 мм; $8-0$ и 8 мм;

6 - с различными по свойствам упрочненными слоями: 1 - однородный образец из стали $40 \mathrm{X}$ в исходном состоянии; 2 - однородный образец из стали 40Х, закаленный в масло и отпущенный; 3 - однородный образец из стали 40X, закаленный в воду; 4 - двухслойный образец, составленный из материалов 1 и 2; 5 - двухслойный образец, составленный из материалов 1 и 3

Более подробно влияние переходной зоны на формирование пиков на полевых зависимостях $\mu_{\mathrm{d}}(H)$ рассмотрено в работе [13] на примере стали 20 после цементации и закалки в масло (табл. 1), а также при изучении характера изменения твердости по толщине образца (рис. 3) и проведении послойного стачивания с одновременной регистрацией дифференциальной магнитной проницаемости (рис. 4).

Дюрометрические и микроструктурные исследования показывают, что цементованный слой, общая толщина которого $x_{0}=2,0$ мм, а эффективная толщина $x_{\ni}=0,7$ мм, состоит из двух зон: поверхностной зоны с твердостью $630 \ldots 530 \mathrm{HV}$ глубиной до 0,5 мм и переходной зоны на 
глубине от 0,5 до 1,2 мм с твердостью от 500 до $250 \mathrm{HV}$ и градиентной структурой, переходящей от сорбита с прослойками избыточного цементита и включениями остаточного аустенита к феррито-перлитной сердцевине. Пониженная твердость поверхностного слоя глубиной до 0,1 мм объясняется обезуглероживанием и окислением тонкого поверхностного слоя при газовой цементации [14]. Внутреннее окисление считается неустранимым дефектом, но вследствие проникновения на небольшую глубину он может быть удален при шлифовке [15]. Отметим, что толщина обезуглероженного окисленного слоя в нашем случае приблизительно соответствует припуску, обычно удаляемому при зубошлифовании колес для обеспечения рациональной структуры цементованного слоя и наибольшего сопротивления контактной усталости.

Таблица 1 - Твердость, структура и магнитные характеристики стали 20 без цементации и после цементации в течение 15 ч и последующей закалки в масло

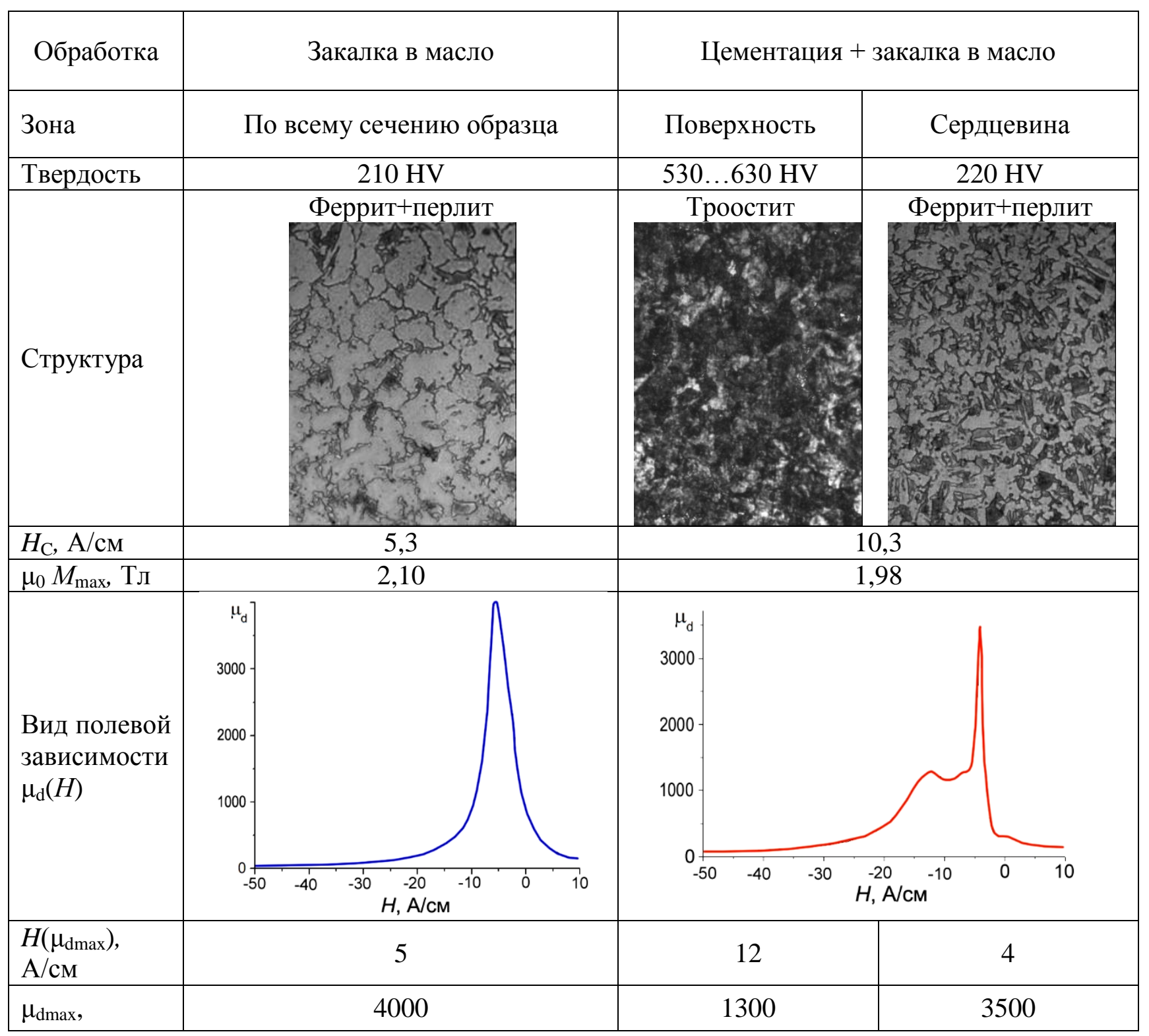




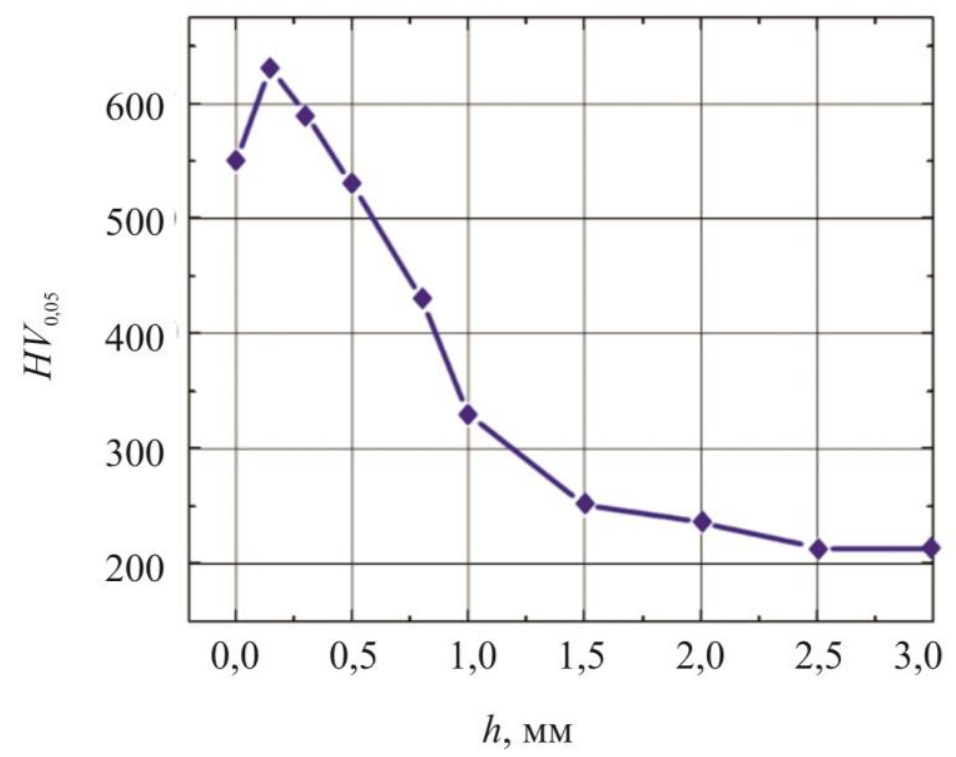

Рис. 3. Микротвердость в поперечном сечении рабочей части образца стали 20 после цементации в течение 15 ч и закалки в масло

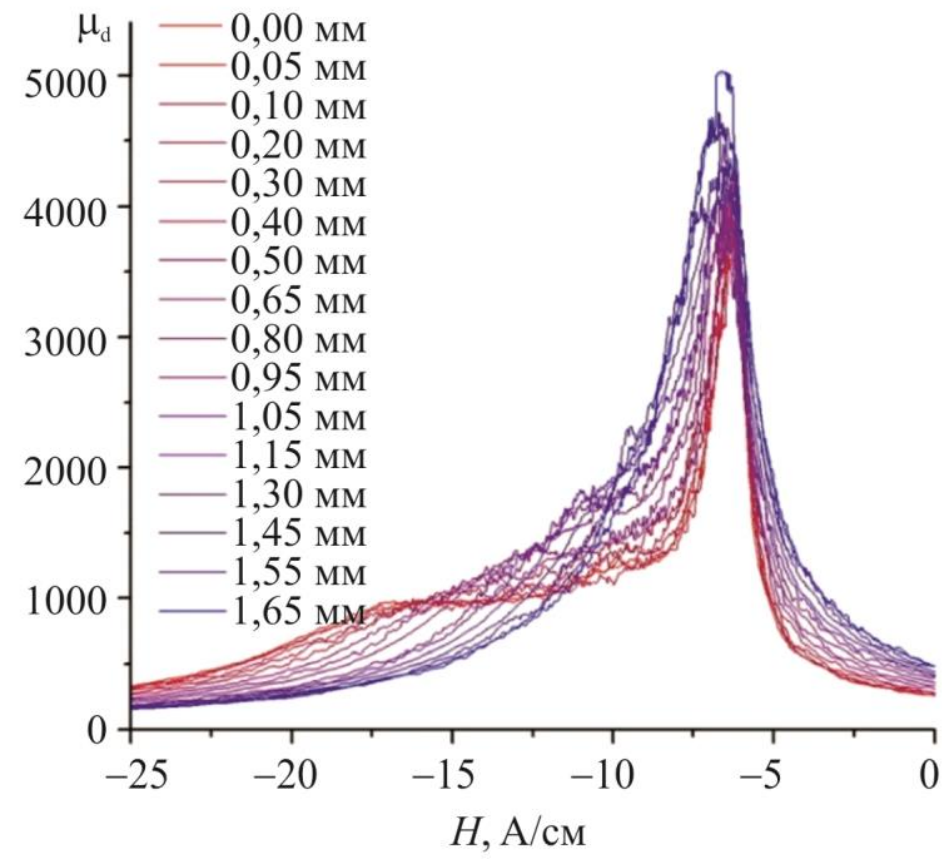

Рис. 4. Влияние послойного стачивания поверхностного слоя толщиной от 0,05 до 1,65 мм на полевые зависимости дифференциальной магнитной проницаемости $\mu_{\mathrm{d}}(H)$ образца стали 20 после цементации и закалки в масло

Послойное стачивание с поверхности образца слоя (рис. 4) толщиной от 0,05 до 1,65 мм путем токарной обработки с охлаждением показало, что максимум дифференциальной магнитной проницаемости в полях $17,5 \ldots 18 \mathrm{~A} / \mathrm{cm}$ соответствует наиболее упрочненному (до $600 \ldots 630$ HV) подповерхностному слою, локализованному на глубине 0,25...0,40 мм, именно поэтому удаление с поверхности первых 0,1 мм (обезуглероженный окисленный слой) не приводит к изменениям на полевой зависимости $\mu_{\mathrm{d}}(H)$. Четко выраженный пик в полях $4 \mathrm{~A} / \mathrm{cm}$ отвечает феррито-перлитной сердцевине (табл. 1), и по мере снятия поверхностного слоя его высота закономерно увеличивается, что отмечалось нами ранее для стали 45 , термоупрочненной 
лазером $[16,17]$. Отличительной особенностью полученной в настоящей работе полевой зависимости $\mu_{\mathrm{d}}(H)$ является появление на кривой $\mu_{\mathrm{d}}(H)$ площадки в полях $8 \ldots 9$ А/см, которая соответствует переходному слою. Наблюдение такой площадки на полевой зависимости стало возможным благодаря двум факторам. Во-первых, сердцевина и поверхностный слой значительно отличаются по содержанию углерода и по магнитным свойствам, поэтому соответствующие им пики $\mu_{\mathrm{d}}$ расположены достаточно далеко один от другого. Во-вторых, переходный слой характеризуется значительной толщиной $(0,6 \ldots 0,8$ мм).

На рис. 5 показано схематическое представление того, каким образом три слоя цементованного образца, отличные по структуре и физическим свойствам (кривая 1 - сердцевина образца; кривая 2 - поверхностный слой; кривая 3 - переходная зона), могут сформировать экспериментально наблюдаемую полевую зависимость дифференциальной магнитной проницаемости (кривая 4).

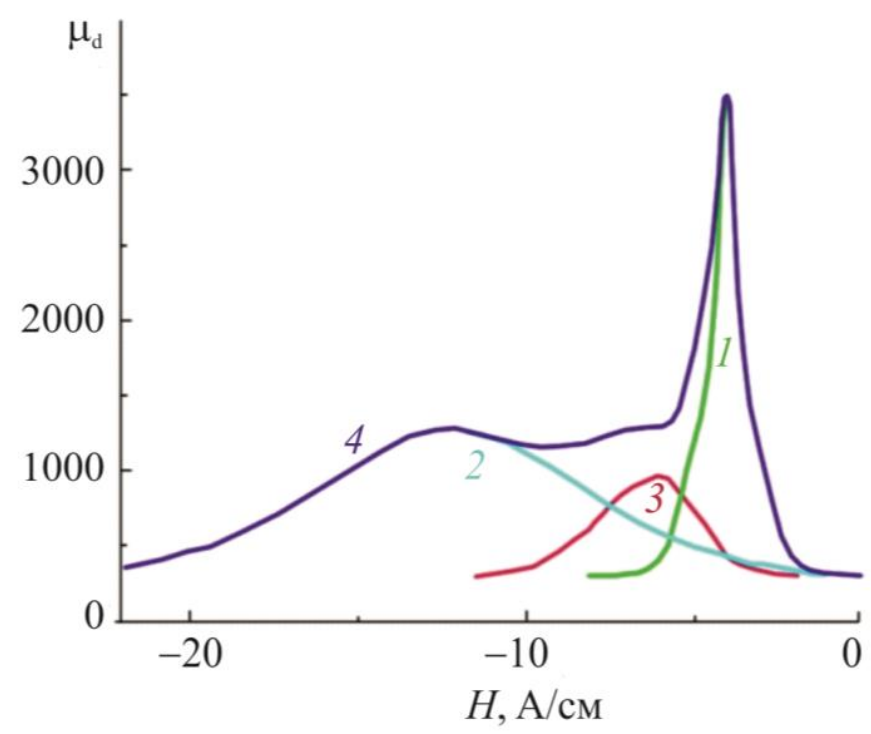

Рис. 5. Схема формирования картины пиков на полевой зависимости дифференциальной магнитной проницаемости $\mu_{\mathrm{d}}(H)$ стали 20 после цементации и закалки в масло:

1 - сердцевина образца; 2 - поверхностный слой; 3 - переходная зона; 4 - экспериментально наблюдаемая картина

\section{3. Сварные соединения}

Еще одним из видов композиционного материала можно представить сварное соединение, которое содержит основной металл, зону термического влияния (ЗТВ) и сварной шов [18].

Исследования проводили на двух плоских образцах, имеющих следующие размеры: длина 200 мм, ширина 45 мм и толщина 4,4 мм. Пластины были вырезаны из прямошовной трубы Ø1420×21,6 мм, изготовленной из листовой стали класса прочности X70, прокатанной по технологии контролируемой прокатки и содержащей в себе клинообразный сварной шов. Образцы были вырезаны на разных расстояниях от поверхности металла, при этом на каждой стороне полученных пластин были зафиксированы части клинообразного сварного шва, что позволило получить образцы с различной шириной сварного шва.

Химический состав исследованной стали представлен в табл. 2, из данных которой следует, что металл сварного шва содержит значительно больше углерода, кремния и никеля, чем основной металл. 
Таблица 2 - Химический состав исследованной стали контролируемой прокатки класса прочности X70 и шва сварного соединения

\begin{tabular}{|l|c|c|c|c|c|c|c|c|c|c|c|}
\hline \multicolumn{10}{|c|}{ Массовая доля элементов, \% } \\
\hline Материал & $\mathrm{C}$ & $\mathrm{Mn}$ & $\mathrm{Si}$ & $\mathrm{S}$ & $\mathrm{P}$ & $\mathrm{Cr}$ & $\mathrm{Ni}$ & $\mathrm{Mo}$ & $\mathrm{V}$ & $\mathrm{Al}$ & $\mathrm{Nb}$ \\
\hline $\begin{array}{l}\text { Основной } \\
\text { металл }\end{array}$ & 0,06 & 1,62 & 0,18 & 0,003 & 0,015 & 0,04 & 0,02 & 0,24 & 0,068 & 0,04 & 0,05 \\
\hline $\begin{array}{l}\text { Материал } \\
\text { шва }\end{array}$ & 0,1 & 1,58 & 0,45 & 0,003 & 0,016 & 0,033 & 0,232 & 0,335 & 0,006 & 0,024 & 0,017 \\
\hline
\end{tabular}

На рис. $6 a$ и $б$ педставлены полевые зависимости дифференциальной магнитной проницаемости $\mu_{\mathrm{d}}(H)$ для образцов 1 и 2 соответственно, измеренные с помощью гистерезисграфа Remagraph C-500 в замкнутой магнитной цепи для различных вариантов изменения ширины всего образца (т. е. различных соотношений объемов металла ЗТВ и металла сварного шва).

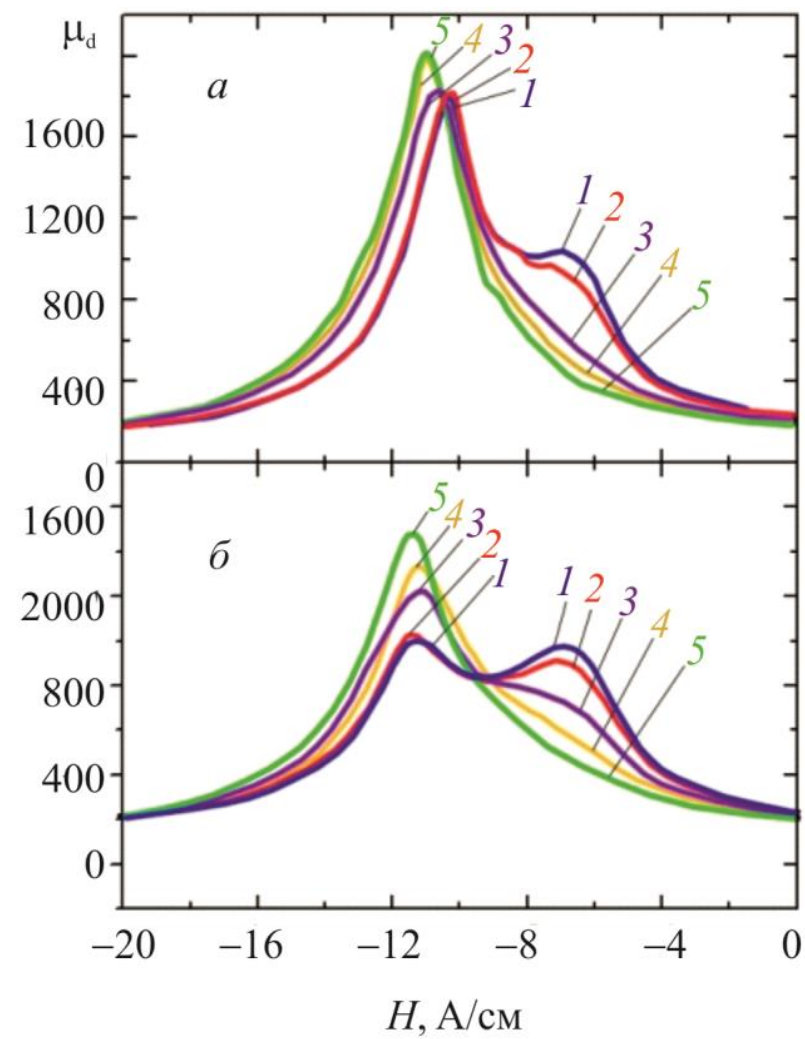

Рис. 6. Полевые зависимости дифференциальной магнитной проницаемости для различных вариантов изменения ширины всего образца:

$a$ - образец № $1 ; \sigma$ - образец № 2. Ширина образца: $1-45 ; 2-40 ; 3-30 ; 4-25 ; 5-20$ мм

Измерительная катушка индукции охватывала центральную часть образцов. Магнитные свойства сварного шва существенно отличаются от свойств металла ЗТВ. Эти различия наиболее отчетливо проявляются на кривых $\mu_{\mathrm{d}}(H)$, на которых, как видно на рис. $6 a, \sigma$, можно наблюдать наличие двух максимумов, характерных для двухкомпонентных образцов. На рис. $6 a$, $\sigma$ показаны только те участки полевых зависимостей, на которых формируются пики. Максимумы дифференциальной магнитной проницаемости, отвечающие сварному шву, локализуются в более сильных полях, и их высота заметно больше, чем у пиков, отвечающих металлу ЗТВ. Как известно, напряженности полей, в которых наблюдаются максимумы дифференциальной магнитной проницаемости, связаны со структурным состоянием компонентов и по величине близки к их коэрцитивным силам $[4,5,11]$. В нашем случае пики локализуются при величинах напря- 
женности магнитного поля 7 и $11 \mathrm{~A} /$ см соответственно для металла ЗТВ и сварного шва в случае как первого, так и второго образца.

В свою очередь по изменениям соотношения величин максимумов зависимостей дифференциальной магнитной проницаемости, как известно $[6,16]$, можно судить об относительном изменении содержания того или иного компонента в двухкомпонентном образце. Для того чтобы проводить диагностику состояния какого-либо компонента двухкомпонентного материала, необходимо оценить, какое минимальное содержание этого компонента в контролируемом объеме материала будет достаточным для проведения диагностики. В табл. 3 приведены значения процентного содержания объема материала сварного шва и объема материала ЗТВ в контролируемом объеме образца, т. е. в объеме, участвующем в формировании сигнала катушки индукции гистерезисграфа, на каждом шаге изменения размеров образцов.

Таблица 3 - Изменение размеров образцов, процентное содержание объема материала сварного шва и объема материала ЗТВ в контролируемом объеме образца

\begin{tabular}{|c|c|c|c|}
\hline $\begin{array}{c}\text { № } \\
\text { шага }\end{array}$ & $\begin{array}{c}\text { Ширина } \\
\text { образца, } \\
\text { мм }\end{array}$ & $\begin{array}{c}\text { Процентное содержание объема } \\
\text { материала сварного шва } \\
\text { (объема материала 3ТВ) } \\
\text { в контролируемом объеме } \\
\text { образца № 1, \% }\end{array}$ & $\begin{array}{c}\text { Процентное содержание объема } \\
\text { материала сварного шва } \\
\text { (объема материала 3ТВ) } \\
\text { в контролируемом объеме } \\
\text { образца № 2, \% }\end{array}$ \\
\hline 1 & 45 & $46(54)$ & $23(77)$ \\
\hline 2 & 40 & $52(48)$ & $26(74)$ \\
\hline 3 & 30 & $69(31)$ & $34(66)$ \\
\hline 4 & 25 & $83(17)$ & $41(59)$ \\
\hline 5 & 20 & $91(9)$ & $51(49)$ \\
\hline
\end{tabular}

Из данных рис. $6 a$, $б$ следует, что по мере уменьшения ширины образца величина пиков дифференциальной магнитной проницаемости, соответствующих металлу ЗТВ, снижается и при определенном процентном содержании данного материала пик, ей соответствующий, становится неразличимым, в то время как величина максимумов, соответствующих металлу сварного шва, растет. Такой характер поведения максимумов был отмечен при изменении размеров обоих образцов. Отсутствие пика ЗТВ в случае образца № 1 наблюдается на 3-м шаге (кривая 3 рис. 6 a) при содержании объема данного материала, равном 31 \%, а в случае образца № 2 - на 5-м шаге измерений (кривая 5 рис. 6 б) при 49 \%. Следовательно, в нашем случае информацию о свойствах металла ЗТВ можно получить по измерениям дифференциальной магнитной проницаемости, если процентное содержание объема этого материала в контролируемом объеме образца составляет более $60 \%$.

\section{4. Упругие и пластические деформации}

Метод наблюдения за изменением характера полевых зависимостей дифференциальной магнитной проницаемости $\mu_{\mathrm{d}}(H)$ может быть использован для оценки процессов, происходящих при упругой и пластической деформации многослойных элементов конструкций. Для контроля состояния отдельных компонентов многослойного изделия и оценки их остаточного ресурса предлагаем использовать в качестве информативной характеристики величину поля максимальной дифференциальной магнитной проницаемости $H_{\mu_{\mathrm{d}} \max }$ магнитомягкого и магнитотвердого компонентов составного изделия (рис. 7).

Влияние одноосного растяжения на магнитные свойства изучали [19] на плоских образцах из стали 45 после закалки $\left(850{ }^{\circ} \mathrm{C}\right.$, масло) с отпуском $\left(350{ }^{\circ} \mathrm{C}, 2\right.$ ч) и из стали 
Ст3, отожженной при $800{ }^{\circ} \mathrm{C}$ (2 ч, охлаждение с печью), а также на двухслойном составном образце, скомпонованном из указанных пластин с различной степенью магнитной твердости. В двухслойном образце пластины были жестко соединены между собой в местах захвата зажимами испытательной машины путем клепки.

Геометрические размеры рабочей части образцов и их магнитные характеристики в исходном состоянии представлены в табл. 4.

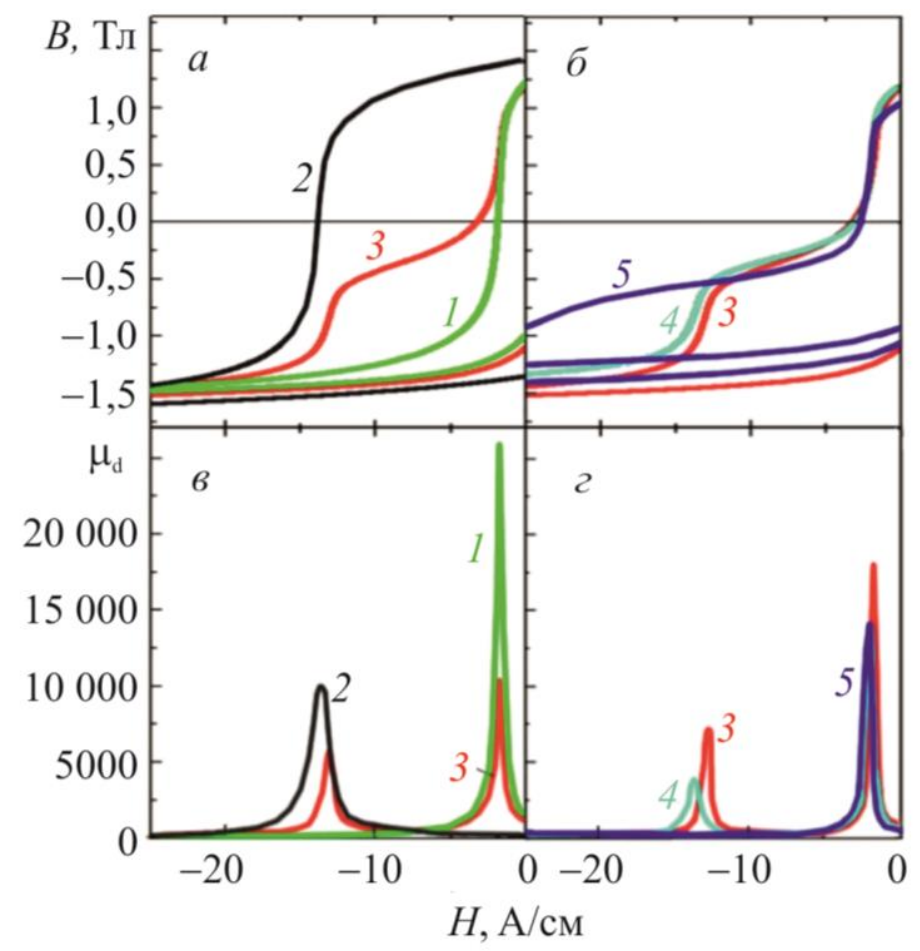

Рис. 7. Нисходящие ветви предельных петель магнитного гистерезиса отдельных компонентов (кривые 1 и 2) и составного образца (кривая 3) (a), а также соответствующие им полевые зависимости дифференциальной магнитной проницаемости (в) в исходном состоянии. Нисходящие ветви предельных петель магнитного гистерезиса (б) и полевые зависимости дифференциальной магнитной проницаемости (2) составного образца в исходном состоянии (3), при внешних напряжениях, составляющих 0,5 от напряжения разрушения магнитотвердого компонента (4) и непосредственно перед разрушением магнитотвердого компонента (5)

Таблица 4 - Геометрические размеры рабочей части образцов и их магнитные характеристики в исходном состоянии

\begin{tabular}{|c|l|c|c|c|}
\hline № п.п. & \multicolumn{1}{|c|}{ Образец } & Размеры, мм & $H_{\mathrm{C}}, \mathrm{A} / \mathrm{cm}$ & $B_{\mathrm{r}}, \mathrm{T}$ \\
\hline 1 & Ст3 (отжиг) & $90 \times 25 \times 2,04$ & 1,8 & 1,11 \\
\hline 2 & 45 (закалка + отп.) & $90 \times 25 \times 1,20$ & 13,6 & 1,37 \\
\hline 3 & $\begin{array}{l}\text { Составной образец: } \\
\text { Ст3 (отжиг) + 45 (закалка + отп.) }\end{array}$ & $90 \times 25 \times(2,14+1,10)$ & 3,0 & 1,14 \\
\hline
\end{tabular}

Снижение толщины магнитотвердой пластины приблизительно в два раза по сравнению с магнитомягкой пластиной было обусловлено ограниченным усилием испытательной машины. 
На рис. $7 a$, $б$ показаны предельные полупетли магнитного гистерезиса составного образца (табл. 4) и входящих в него компонентов 1 и 2 (измеренных по отдельности), а также соответствующие им полевые зависимости дифференциальной магнитной проницаемости в исходном состоянии (до начала нагружения). Петля гистерезиса составного образца (кривая 3 на рис. 7 a) имеет вид, характерный для двухслойного ферромагнетика [16] и отличается от петель гистерезиса для однородных материалов (кривые 1 и 2), в частности, наличием двух перегибов. Один из них, локализующийся в области меньших полей, соответствует магнитомягкому компоненту, а другой - магнитотвердому. Механизм образования подобных перегибов был описан в работах [8-10]. На полевой зависимости дифференциальной магнитной проницаемости такие перегибы проявляются в виде максимумов (пиков) дифференциальной магнитной проницаемости (рис. 7 в). Количество таких пиков соответствует числу слоев с различной магнитной твердостью, а соотношение высот пиков определяется, в частности, соотношением толщины соответствующих слоев [10, 20].

На рис. 7 б, г показана эволюция предельных петель магнитного гистерезиса составного образца (табл. 4) и изменение вида полевых зависимостей максимальной магнитной проницаемости. Чтобы не усложнять рисунки, на них приведены кривые, соответствующие только трем точкам диаграммы «напряжение-деформация»: кривые 3 соответствуют исходному состоянию, кривые 4 сняты при внешних напряжениях, составляющих 0,5 от напряжения разрушения магнитотвердого компонента, и кривые 5 получены непосредственно перед разрушением магнитотвердого компонента. Из рис. 7 г следует, что в процессе деформации пик магнитотвердого компонента на полевой зависимости максимальной магнитной проницаемости смещается в область более сильных полей и, кроме того, становится менее интенсивным и более уширенным. Пик магнитомягкого компонента также смещается в область более сильных полей, но в силу малой абсолютной величины смещения (по сравнению с пиком магнитотвердого компонента) на полевой зависимости это смещение менее заметно. При этом перегибы предельной петли также смещаются в область более сильных полей (см. рис. 7 б).

Влияние растяжения па магнитные свойства двухслойного модельного образца приведено на диаграмме «напряжение-деформация» (рис. 8). Разрушение составного образца всегда происходило путем образования магистральной трещины в пластине, подвергнутой объемной закалке, после чего эксперимент прекращали. Из данных рис. 8 видно, что прочностные характеристики двухслойного образца занимают промежуточное положение между характеристиками составляющих его слоев, а пластичность соответствует пластичности более прочного слоя. С учетом того, что оба слоя составного модельного образца в ходе эксперимента растягиваются на одну и ту же величину, для любого значения относительного удлинения можно рассчитать напряжения в магнитомягком и магнитотвердом слоях по методике, предложенной в [21]:

$$
\begin{aligned}
& \sigma_{1}=E \delta_{11}+E_{1}\left(\delta-\delta_{11}\right) \\
& \sigma_{2}=E \delta_{21}+E_{2}\left(\delta-\delta_{21}\right),
\end{aligned}
$$

где $\delta$ - текущее значение деформации, при которой определяется напряжение; $\delta_{11}$ и $\delta_{21}-$ значения деформации, соответствующие пределам текучести; $E$ - модуль упругости, равный при комнатной температуре $2 \times 10^{5} \mathrm{MПа;} E_{1}$ и $E_{2}$ - тангенсы углов наклона участков пластической деформации соответствующих слоев. С учетом билинейной аппроксимации кривых растяжения $E_{1}$ и $E_{2}$ были вычислены как тангенсы углов наклона $\beta_{1}$ и $\beta_{2}$ на участке пластической деформации: 


$$
\begin{aligned}
& E_{1}=\operatorname{tg} \beta_{1}=\frac{\sigma_{12}-\sigma_{11}}{\delta_{12}-\delta_{11}} ; \\
& E_{2}=\operatorname{tg} \beta_{2}=\frac{\sigma_{22}-\sigma_{21}}{\delta_{22}-\delta_{21}},
\end{aligned}
$$

где $\sigma_{11}, \sigma_{21}$ и $\delta_{11}, \delta_{21}$ - напряжения и деформации, соответствующие пределу текучести; $\sigma_{12}$, $\delta_{12}$ и $\sigma_{22}, \delta_{22}-$ координаты любых точек на участках пластической деформации стали 45 после нормализации и стали 45 после закалки с отпуском соответственно. Для повышения точности расчетов в качестве точек $\sigma_{12}, \delta_{12}$ и $\sigma_{22}, \delta_{22}$ были взяты напряжения и деформации, соответствующие временному сопротивлению.

Для стали 45 после закалки с отпуском: $\sigma_{11}=900 \mathrm{MПа;} \sigma_{12}=1080 \mathrm{MПа;} \delta_{11}=0,0045$; $\delta_{12}=0,025 ; E=2 \cdot 10^{5} \mathrm{MПа;} E_{1}=0,088 \cdot 10^{5} \mathrm{MПа}$.

Для стали 45 после нормализации: $\sigma_{21}=390 \mathrm{MПа;} \sigma_{22}=593 \mathrm{MПа;} \delta_{21}=0,0025$; $\delta_{22}=0,143 ; E=2 \cdot 10^{5} \mathrm{M \Pi а} ; E_{2}=0,0159 \cdot 10^{5}$ МПа.

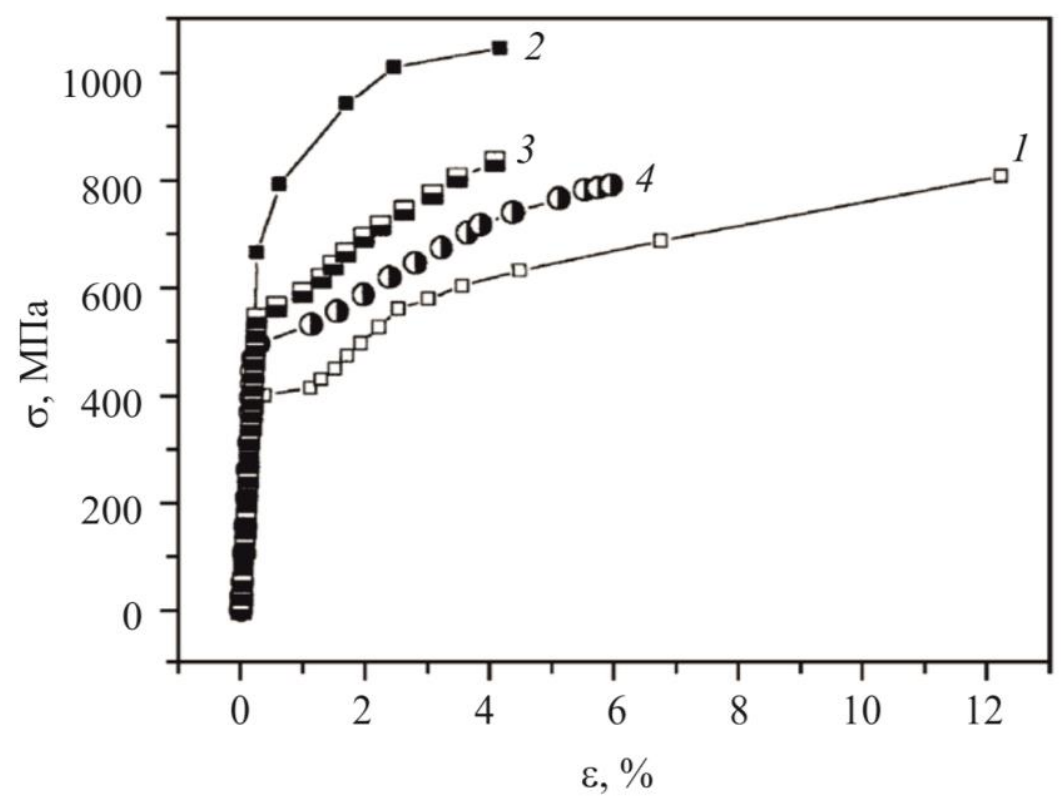

Рис. 8. Диаграммы «напряжение-деформация» исследованных образцов:

1 - сталь 45 после объемной закалки с отпуском; 2 - сталь 45 после нормализации; 3 - модельный двухслойный образец стали 45; 4 - сталь 45, термоупрочненная лазером

Результаты расчетов напряжений в каждом из слоев двухслойного модельного образца как функции достигнутого удлинения приведены на рис. 9 a. Построенные диаграммы напряжений в отдельных компонентах составного образца указывают, в частности, на следующее: 1) существует некоторый интервал удлинения, когда мягкий слой уже деформируется пластически, а деформация твердого слоя еще носит упругий характер; 2) при одной и той же пластической деформации напряжения в твердом слое значительно превышают напряжения, возникающие в мягком слое.

Эти факты находят свое отражение в эволюции полевой зависимости дифференциальной магнитной проницаемости составного образца. На рис. 10 в 3D-представлении представлено изменение картины пиков составного модельного образца с деформацией в случае регистрации петли магнитного гистерезиса под нагрузкой и после разгружения соответственно. При этом на рис. 9 показаны не все экспериментально полученные полевые зависимости магнитной проницаемости, а лишь картины, наиболее характерные для различных стадий растя- 
жения, что позволило избежать усложнения рисунков и при этом наглядно показать трансформацию пиков. Результаты подробных исследований изменения характеристик пиков под действием растягивающих напряжений представлены на рис. 11 и 12.
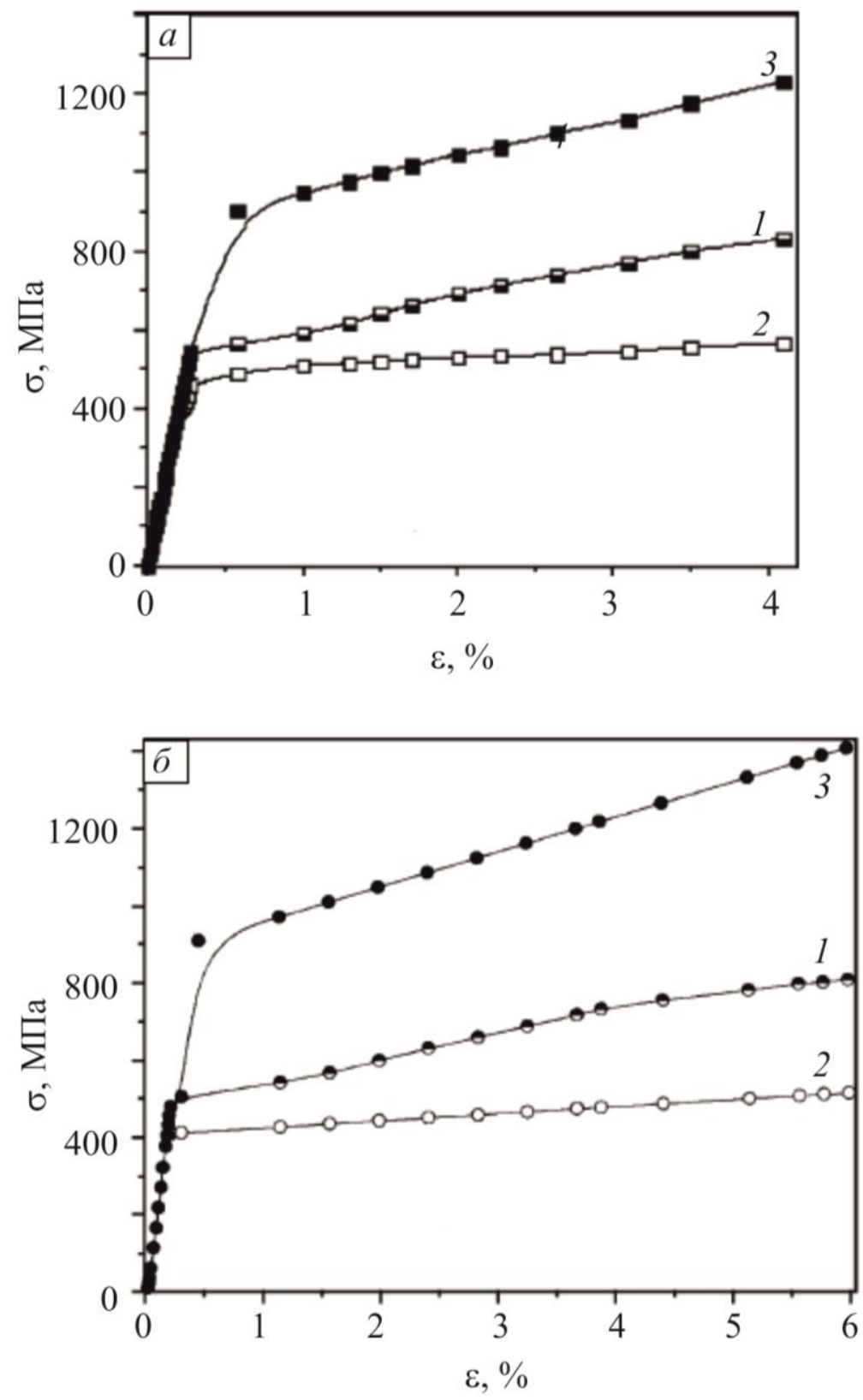

Рис. 9. Диаграммы «напряжение-деформация» для растяжения:

$a$ - двухслойного образца (1), его мягкого слоя (2) и твердого слоя (3);

$\sigma$ - термоупрочненного лазером образца (1), его сердцевины (2) и поверхностного слоя (3).

1 - эксперимент, 2, 3 - расчет 


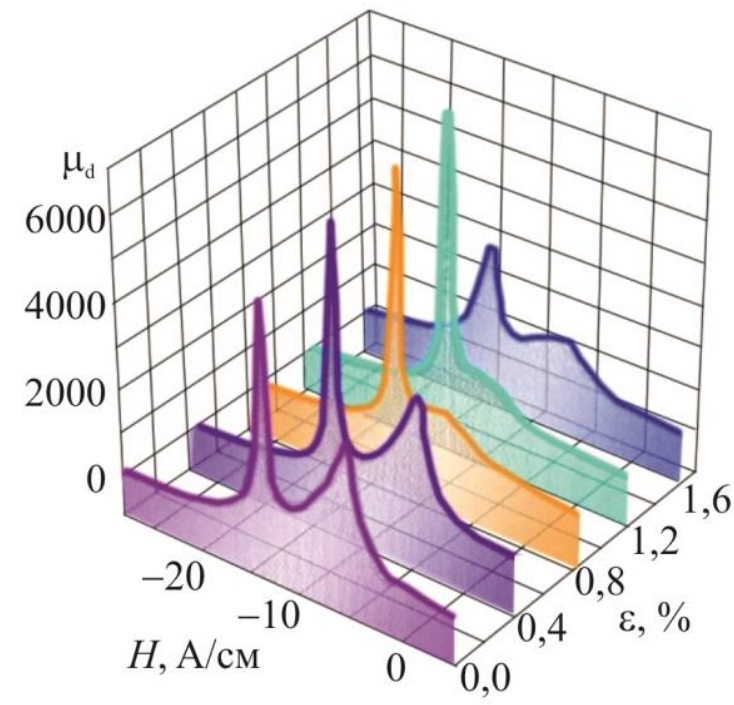

$a$

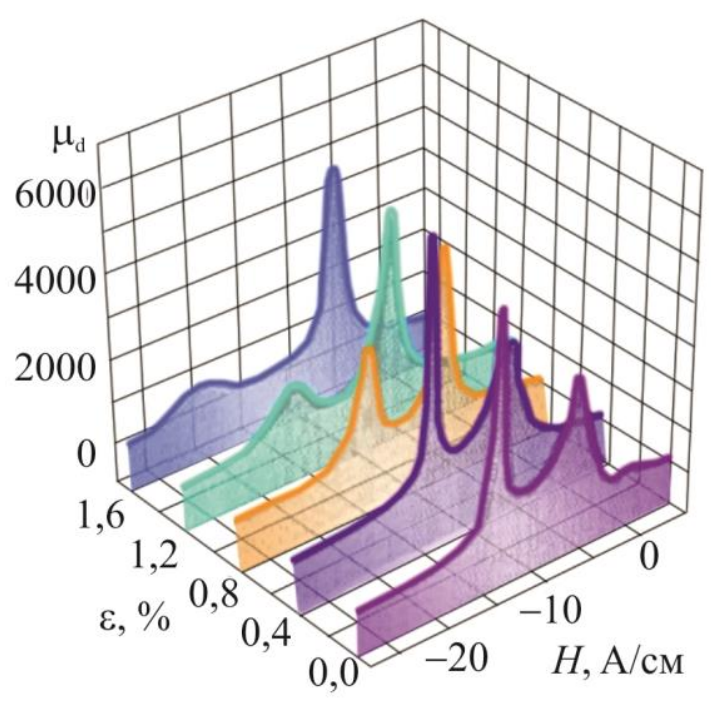

$\sigma$

Рис. 10. Эволюция полевой зависимости дифференциальной магнитной проницаемости двухслойного образца как функция относительного удлинения. Измерения в нагруженном состоянии $(a)$ и после разгружения (б)

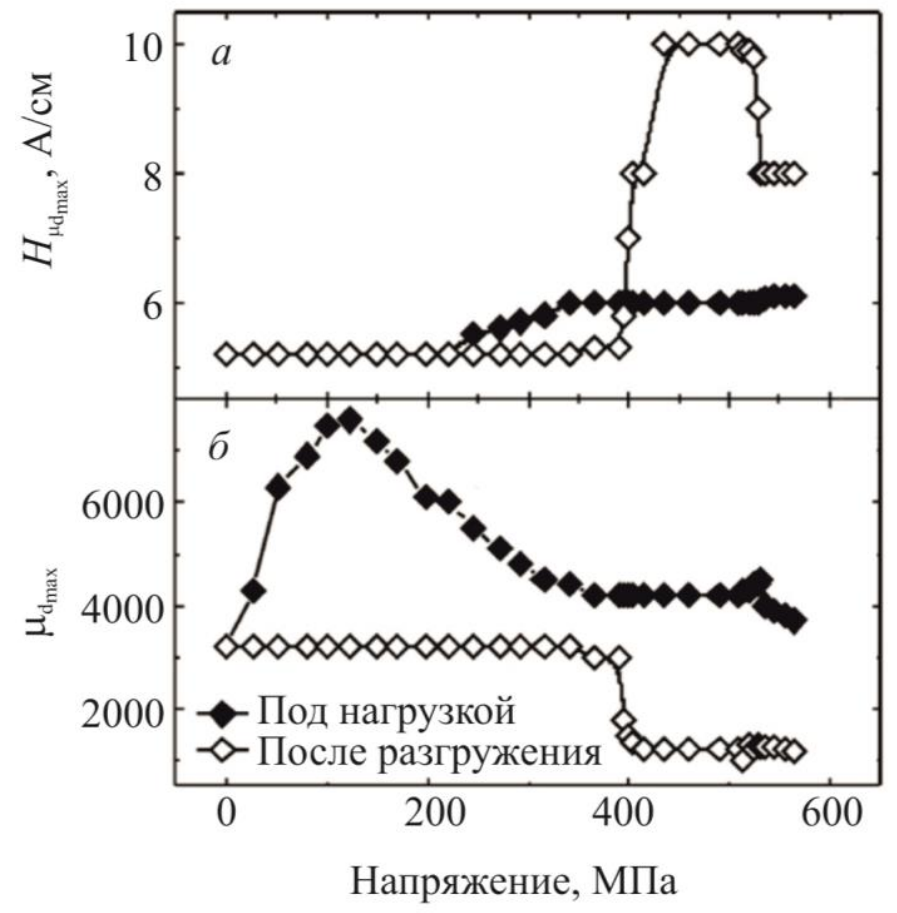

Рис. 11. Зависимости поля пика ( $a$ ) и высоты пика (б) максимальной дифференциальной магнитной проницаемости магнитомягкого слоя двухслойного образца от величины растягивающих напряжений в данном слое

На рис. 11 изменение поля пиков $H_{\mu_{\mathrm{d}_{\max }}}$ и высоты $\mu_{\mathrm{d}_{\max }}$ пиков дифференциальной магнитной проницаемости магнитомягкого слоя составного образца представлено как функция напряжений, возникающих в данном слое при растяжении, темные значки соответствуют магнитным измерениям в нагруженном состоянии, незакрашенные значки - измерениям после снятия нагрузки. Видно, что все представленные кривые имеют перегибы в области напряжений 390-400 МПа, что соответствует пределу текучести $\sigma_{0,2}$ материала данного слоя. При этом 
регистрация петли магнитного гистерезиса под нагрузкой дает двухпараметрический инструмент оценки напряжений в интервале от 0 до 400 МПа. Величину напряжений в мягком слое в пластической области растяжения оценить данным методом не удается, но сам факт превышения предела текучести в предыстории погружения элемента конструкции надежно регистрируется по изменению поля пика $H_{\mu_{\text {max }}^{*}}^{*}$ и высоты пика $\mu_{\mathrm{d}_{\max }}^{*}$ в разгруженном состоянии: в случае превышения величины $\sigma_{0,2}$ указанные характеристики меняются скачкообразно на $100 \%$ и более.

На рис. 12 приведены зависимости поля пика и высоты пика максимальной дифференциальной магнитной проницаемости магнитотвердого слоя двухслойного образца от величины растягивающих напряжений в данном слое. И в этом случае видно, что величина поля пика $H_{\mu_{\mathrm{d}_{\max }}^{*}}$ измеренная на разгруженном образце, претерпевает скачок в области напряжений, соответствующих пределу текучести $\sigma_{0,2}$ данного материала - 900-920 МПа. Рост поля пика $H_{\mu_{\mathrm{d} \text { ax }}}$ при измерении в нагруженном состоянии начинается при напряжениях около $400 \mathrm{MПа}$ и продолжается неуклонно вплоть до разрушения материала, что создаст основу для оценки напряжений, превышающих $(0,4-0,5) \sigma_{0,2}$ данного слоя.

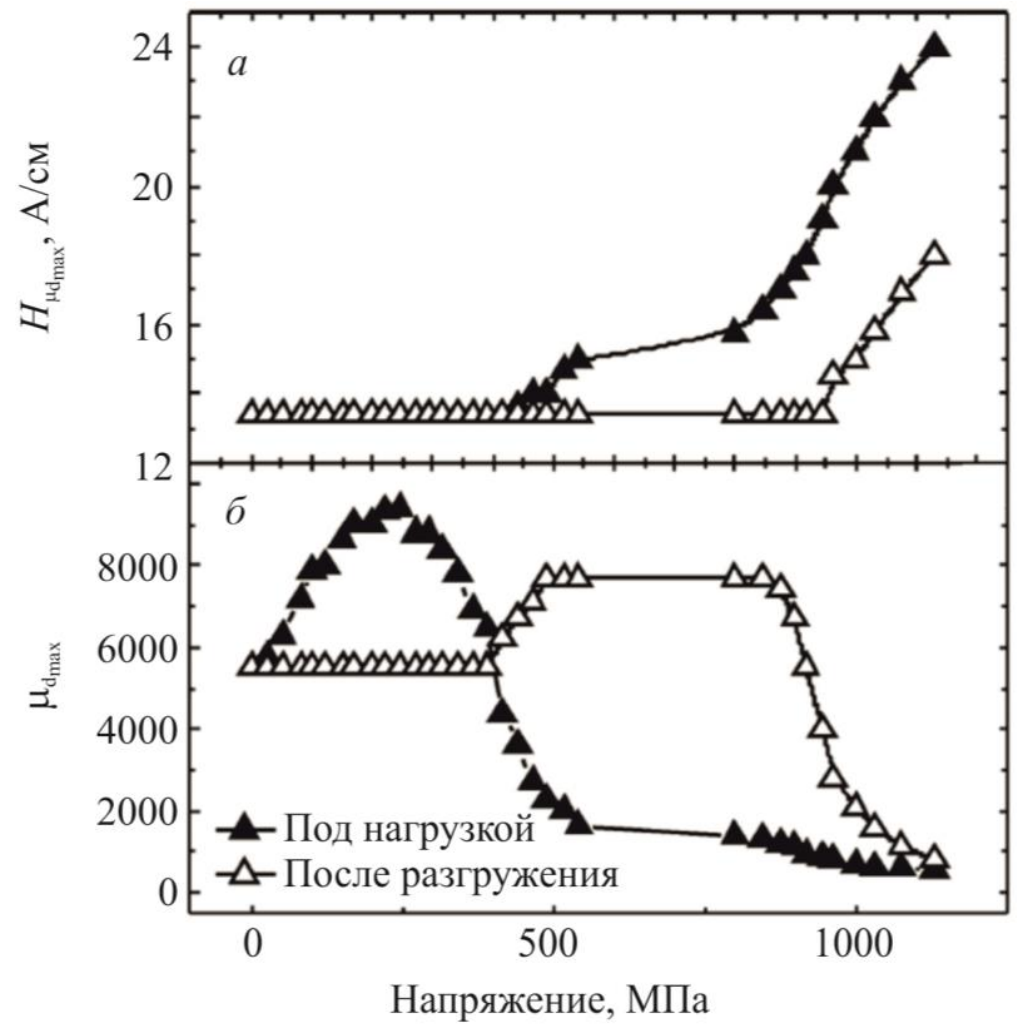

Рис. 12. Зависимости поля пика (a) и высоты пика (б) максимальной дифференциальной магнитной проницаемости магнитотвердого слоя двухслойного образца от величины растягивающих напряжений в данном слое

\section{5. Фазовые превращения}

Используемые в композиционных материалах составляющие компоненты КМ при внешних воздействиях не всегда сохраняют структуру и свойства на необходимом уровне. Например, наиболее часто применяемые коррозионностойкие стали аустенитного класса обладают, как правило, деформационно-нестабильной структурой, в которой при силовом воздействии могут протекать фазовые превращения с образованием в парамагнитной матрице 
ферромагнитных частиц $\alpha^{\prime}$-фазы, что приводит к снижению сопротивления межкристаллитной коррозии $[22,23]$. В связи с этим в процессе изготовления и эксплуатации необходимо диагностировать состояние деталей и элементов конструкций из подобных материалов [24, 25].

Образцы для исследования вырезали из листовых сталей промышленной выплавки марок Ст3 и 08X18Н10Т (листы толщиной 3,9 мм и 1,9 мм соответственно). Химический состав приведен в табл. 5.

Таблица 5 - Химический состав сталей Ст3 и 08Х18Н10Т

\begin{tabular}{|l|c|c|c|c|c|c|c|c|}
\hline \multicolumn{1}{|c|}{ Марка стали } & $\mathrm{C}$ & $\mathrm{Cr}$ & $\mathrm{Ni}$ & $\mathrm{Mn}$ & $\mathrm{Si}$ & $\mathrm{Ti}$ & $\mathrm{S}$ & $\mathrm{P}$ \\
\hline Ст3 & 0,1 & - & - & 0,48 & 0,19 & - & 0,005 & 0,01 \\
\hline 08X18H10T & 0,07 & 17,3 & 8,5 & 0,5 & 0,74 & 0,4 & 0,005 & 0,03 \\
\hline
\end{tabular}

Композиционный материал «сталь 08X18Н10Т - сталь Ст3» был изготовлен по технологии сварки взрывом в заводских условиях. Из КМ и из отдельных листов сталей Ст3 и 08X18Н10Т вырезали прямоугольные пластины размерами 200×20 мм. Далее заготовки из всех трех материалов подвергали прокатке при комнатной температуре вдоль длинной оси. Скорость прокатки составляла примерно 60 мм/с. Степень деформации прокаткой $\varepsilon_{\text {пр }}$ определяли по формуле:

$$
\ln \left(S_{0} / S\right)
$$

где $S_{0}$ - начальная площадь поперечного сечения заготовки; $S$ - площадь поперечного сечения заготовки после прокатки. Заготовки были прокатаны на следующие степени деформации: $\varepsilon_{\text {пр }}=0 ; 0,11 ; 0,20 ; 0,34 ; 0,49 ; 0,63$ (сталь Ст3); $\varepsilon_{\text {пр }}=0 ; 0,19 ; 0,27 ; 0,36 ; 0,45 ; 0,57$

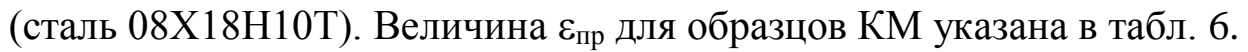

Таблица 6 - Степень деформации прокаткой композиционного материала и каждого слоя в пакете

\begin{tabular}{|l|c|c|c|c|c|c|}
\hline $\begin{array}{c}\text { Деформируемый } \\
\text { материал }\end{array}$ & \multicolumn{6}{|c|}{ Степень деформации, $\varepsilon$} \\
\hline Пакет & 0 & 0,14 & 0,28 & 0,40 & 0,56 & 0,62 \\
\hline 08X18Н10T & 0 & 0,22 & 0,23 & 0,41 & 0,62 & 0,82 \\
\hline Ст3 & 0 & 0,10 & 0,30 & 0,39 & 0,52 & 0,53 \\
\hline
\end{tabular}

Следует отметить, что степень деформации отдельных компонентов в КМ отличается

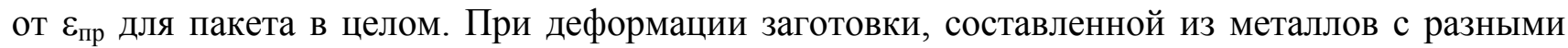
механическими свойствами, в мягком слое появляются дополнительные напряжения сжатия, а в твердых - растяжения. В результате взаимодействия валков с приконтактными поверхностями слоев биметалла в последних возникают сжимающие напряжения. Таким образом, мягкий слой биметалла подвергается действию дополнительных сжимающих напряжений как со стороны твердого слоя, так и со стороны валка [1]. В результате этого деформация мягкого слоя затрудняется, а твердого облегчается, и в КМ степень деформации прокаткой слоя из стали 08Х18Н10Т была выше, чем слоя из стали Ст3.

На рис. 13 приведены полевые зависимости дифференциальной магнитной проницаемости КМ и его составляющих при различных степенях деформации прокаткой. Для образцов из стали Ст3 и композиционного материала в недеформированном состоянии $\left(\varepsilon_{\text {пр }}=0\right)$ на полевой зависимости дифференциальной магнитной проницаемости (рис. 13 a) наблюдается по 
одному пику, соответствующему ферриту в стали Ст3. Магнитная проницаемость стали 08X18Н10T близка к 1. С увеличением степени деформации прокаткой (рис. 13 б) появляются изменения в зависимостях $\mu_{\mathrm{d}}(H)$ для всех трех исследованных материалов. Высота пика на полевой зависимости стали Ст 3 (образец с $\varepsilon_{\text {пр }}=0,34$ ) уменьшается практически в 3 раза. Снижение дифференциальной проницаемости с увеличением степени деформации прокаткой определяется той же причиной, что обусловливает изменение коэрцитивной силы и максимальной магнитной проницаемости, - увеличением плотности дислокаций. На кривой $\mu_{\mathrm{d}}(H)$ для образцов из стали $08 \mathrm{X} 18 \mathrm{H} 10 \mathrm{~T}$, прокатанной до $\varepsilon_{\text {пр }}=0,36$, начинается рост пика, соответствующего формированию при прокатке мартенсита деформации. Пик локализуется в полях 20-25 A/см. Причем на полевой зависимости дифференциальной магнитной проницаемости композиционного материала в этих же полях происходит формирование второго пика, что свидетельствует о протекании фазового превращения в слое из стали 08X18Н10Т в КМ.

На рис. 13 в представлены кривые $\mu_{\mathrm{d}}(H)$ для всех трех материалов, прокатанных на максимальные степени деформации. На кривой $\mu_{\mathrm{d}}(H)$ для композита, прокатанного с $\varepsilon_{\text {пр }}=0,62$, наблюдаются два четких пика, которые соответствуют двум ферромагнитным фазам - ферриту в стали Ст3 и мартенситу в стали 08X18Н10Т. Поля пиков отдельных компонентов с достаточной степенью точности соответствуют значениям их коэрцитивных сил. Пик от стали Ст3, как отдельного компонента, расположен в более сильном поле, чем пик от

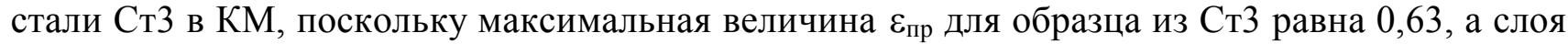
Ст3 в пакете - 0,53 (табл. 6). Пики от стали Ст3 локализуются в полях от 0,2 до $6 \mathrm{~A} / \mathrm{cm}$, а от

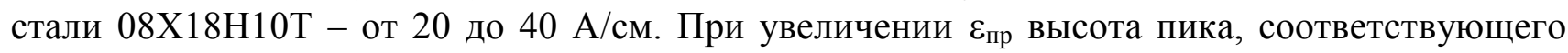
стали 08X18Н10Т, увеличивается с ростом содержания $\alpha^{\prime}$-фазы. Таким образом, по положению пика на полевой зависимости дифференциальной магнитной проницаемости и его высоте можно судить о величине степени деформации прокаткой как композиционного материала в целом, так и его отдельных компонентов.

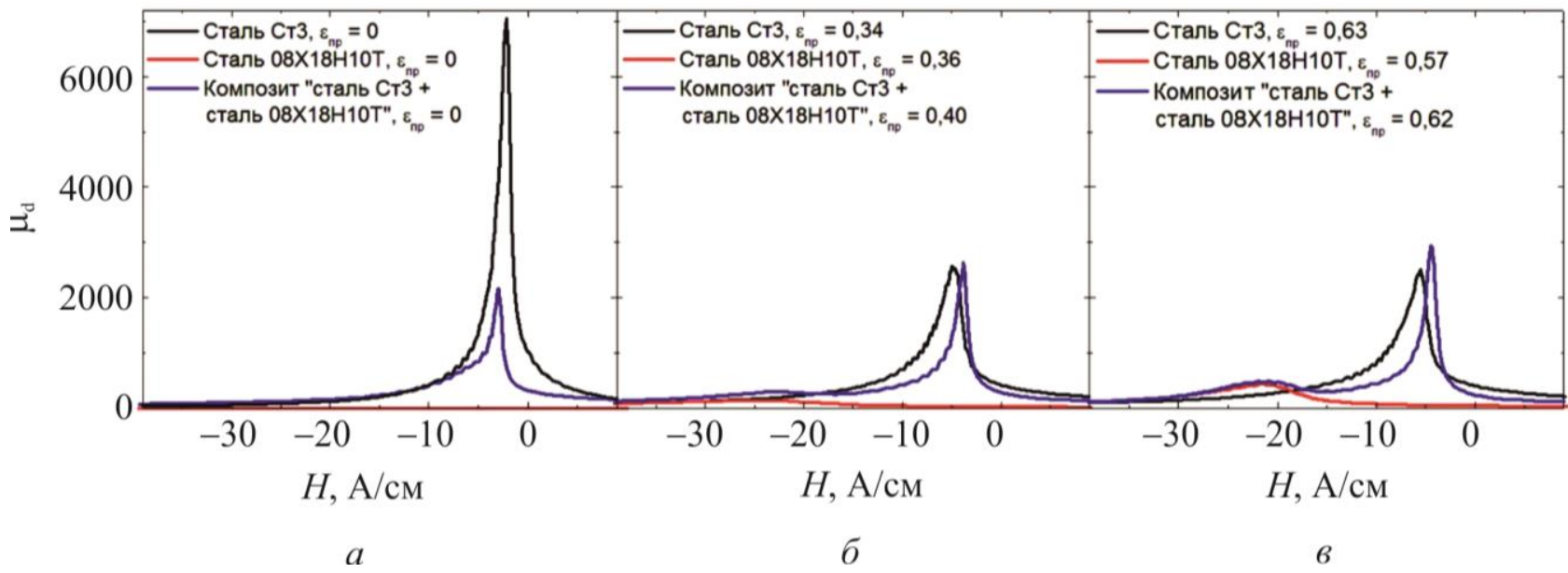

Рис. 13. Полевые зависимости дифференциальной магнитной проницаемости композиционного материала «сталь 08X18Н10Т - сталь Ст3» и его отдельных компонентов, построенных для различных степеней деформации прокаткой

Поскольку величины коэрцитивной силы, максимальной магнитной проницаемости и остаточной индукции композиционного материала почти полностью определяются слоем из стали Ст3, эти характеристики не могут быть использованы для оценки изменений, происходящих при одноосном растяжении в слое из стали 08X18Н10Т в композите. Более информативной для диагностики состояния отдельных компонентов в КМ является полевая зависимость дифференциальной магнитной проницаемости. На рис. 14 приведены полевые зависимости дифференциальной магнитной проницаемости образцов из композиционного матери- 
ала, полученного по технологии сварки взрывом, в исходном состоянии и после прокатки с $\varepsilon_{\text {пр }}=0,62$ при различных приложенных растягивающих напряжениях. У не деформированного прокаткой образца (рис. $14 a$ ) на полевых зависимостях $\mu_{\mathrm{d}}$ наблюдается только один пик, соответствующий ферриту в стали Ст3. То есть разрушение этого образца происходит раньше, чем успевает образоваться достаточное для появления второго пика количество $\alpha^{\prime}-$ мартенсита. У образца с $\varepsilon_{\text {пр }}=0,62$ (рис. 14 б) на полевой зависимости дифференциальной магнитной проницаемости четко различаются два пика, соответствующие двум ферромагнитным фазам: ферриту в стали Ст3 и $\alpha^{\prime}$-мартенситу в стали 08X18Н10T. С увеличением приложенных растягивающих напряжений происходит рост пика $\mu_{\text {диф }}$ от мартенсита деформации по высоте, что свидетельствует об увеличении количества $\alpha$-фазы. Поле пика от мартенсита деформации при приложении растягивающих напряжений изменяется с минимумом. Полевые зависимости дифференциальной магнитной проницаемости, аналогичные приведенным на рис. 14 б, наблюдали для всех образцов, подвергнутых предварительной холодной прокатке.

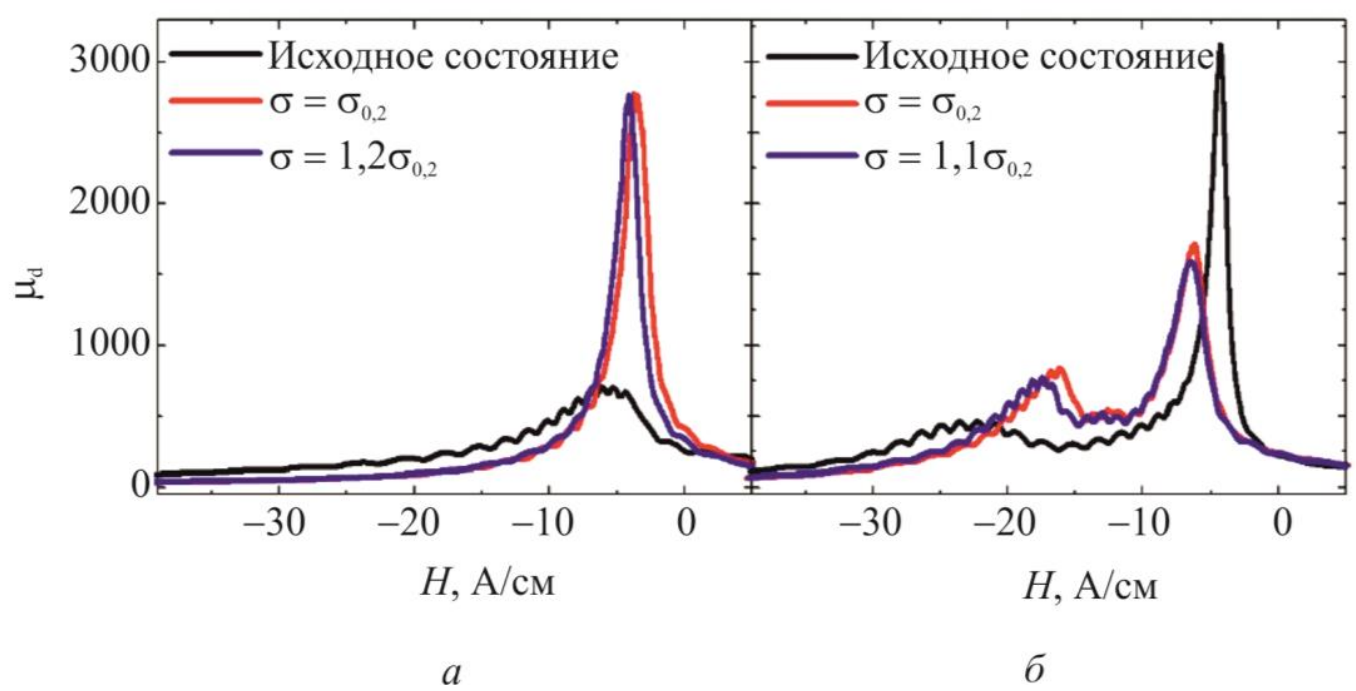

Рис. 14. Полевые зависимости дифференциальной магнитной проницаемости композиционного материала «сталь 08Х18Н10Т - сталь Ст3» в исходном состоянии (a) и после прокатки с $\varepsilon_{\text {пр }}=0,62$ при различных уровнях приложенных растягивающих напряжений (б)

\section{6. Заключение}

Таким образом, магнитные методы контроля могут быть применены для оценки структурного состояния, фазового состава, прочностных характеристик и качества отдельных слоев композиционного материала на основе использования особенностей перемагничивания многослойных ферромагнетиков. Регистрация дифференциальной магнитной проницаемости каждого из слоев расширяет функциональные возможности магнитных методов контроля и позволяет создать приборы для раздельного определения физ ико-механических свойств каждого из слоев и их толщин. В процессе деформационного воздействия, наблюдая за изменениями дифференциальной магнитной проницаемости каждого из слоев, можно судить о характере протекания деформационных процессов в них, а в некоторых случаях оценивать изменения фазового состава в сталях аустенитного класса с деформационно-нестабильной структурой. 


\section{Благодарность}

Работа выполнена при поддержке проектов УрО РАН № 15-10-1-22 и № 15-15-1-52.

\section{Литература}

1. Слоистые металлические композиции / И. Н. Потапов, В. Н. Лебедев, А. Г. Кобелев, Е. В. Кузнецов, А. А. Быков, Р. М. Ключников // М. : Металлургия, 1986. - 216 с.

2. Лахтин Ю. М., Леонтьева В. П. Материаловедение. - М. : Машиностроение, 1990. - 528 с.

3. Application of differential magnetic permeability in the quality control of surface hardening / E. S. Gorkunov, B. M. Lapidus, A. V. Zagainov, S. A. Voronov, G. Y. Bushmeleva // Soviet Journal of Nondestructive Testing-USSR. - 1988. - Vol. 24, no. 7. - P. 441-446.

4. Горкунов Э. С., Лапидус Б. М. Магнитные свойства двуслойных ферромагнетиков применительно к контролю качества поверхностно-упрочненных изделий // Структурно-фазовые превращения в металлах: проблемы прочности и пластичности. - Свердловск : УНЦ АН CCCP, 1987. - C. 103-110.

5. Gorkunov E. S Magnetic Methods and Instruments for the Quality-Control of the CaseHardening of Ferromagnetic Steel Objects - (Review) // Soviet Journal of Nondestructive TestingUSSR. - 1991. - Vol. 27, no. 1. - P. 1-18.

6. Горкунов Э. С., Лапидус Б. М., Загайнов А. В. Способ контроля качества многослойных ферромагнитных изделий. - Авт. свид. № 1252718. - Бюл. изобр., 1986, № 31, с. 182.

7. Щербинин В. Е., Горкунов Э. С. Магнитный контроль качества металлов. - Екатеринбург : УрО РАН, 1996. - 264 с. - ISBN 5-7691-0655-7.

8. Определение глубины закаленного слоя магнитным методом / В. М. Дехтяр, А. М. Горбунова, Л. М. Балдина, Г. М. Касаткина // Заводская лаборатория. - 1946. - Т. 12, № 9-10. - С. 808-816.

9. Дехтяр В. М. О коэрцитивной силе двуслойного цилиндра // ЖЭТФ. - 1946. - Вып. 10. С. 2-7.

10. Михеев М. Н., Горкунов Э. С. Магнитные методы структурного анализа и неразрушающего контроля. - М. : Наука, 1993. - 252 с.

11. Кифер И. И., Семеновская И. Б., Фомин И. Н. О связи дифференциальной проницаемости с коэрцитивной силой // Заводская лаборатория. - 1969. - № 10. - С. 1191-1193.

12. Non-destructive testing for evaluating integrity / K. Brinksmeier, E. Scheider, W. A. Theiner, H. K. Tönsholff // Annals of the CIRP. - 1984. - Vol. 33, № 2. - P. 489-509.

13. Effect of Elasto-Plastic Loading on the Magnetic Characteristics of Steel 20 Hardened with Gas Case-Hardening / E. S. Gorkunov, S. Yu. Mitropolskaya, E. M. Groznaya, A. N. Mushnikov, A. L. Osintseva, E. A. Tueva // Russian Journal of Nondestructive Testing. - 2011. - Vol. 47, no. 4. P. 221-231. - DOI: 10.1134/S106183091104005X.

14. Ryzhov N. M., Fakhurtdinov R. S., Smirnov A. E. Cyclic Strength of Steel 16kh3nvfbm-Sh (Vks-5) after Vacuum Carburizing // Metal Science and Heat Treatment. - 2010. - Vol. 52, nos. 1-2. P. 61-66. - DOI: 10.1007/s11041-010-9230-9.

15. Борисенок Г. В., Васильев Л. А., Ворошнин Л. Г. Химико-термическая обработка металлов и сплавов. - М. : Металлургия, 1981. - 424 с.

16. Effect of Laser Surface Hardening on Magnetic Characteristics of a Carbon Steel under Loading / E. S. Gorkunov, S. Yu. Mitropol'skaya, S. M. Zadvorkin, A. L. Osintseva, D. I. Vichuzhanin // Russian Journal of Nondestructive Testing. - 2008. - Vol. 44, no. 8. - P. 560-565. DOI: $10.1134 /$ S1061830908080081.

17. Magnetic investigation of strains and stresses in surface-hardened materials / E. S. Gorkunov, S. Yu. Mitropolskaya, A. L. Osintseva, D. I. Vichuzhanin // Physical Mesomechanics. - 2009. Vol. 12, iss. 3-4. - P. 190-198. - DOI: 10.1016/j.physme.2009.07.012. 
18. Determination of the Magnetic Properties of Separate Zones of Welds and the Width of Welded Joints Based on Magnetic Measurements / E. S. Gorkunov, A. M. Povolotskaya, E. A. Tueva, L. S. Goruleva, S. M. Zadvorkin // Russian Journal of Nondestructive Testing. - 2011. Vol. 47, no. 9. - P. 577-586. - DOI: 10.1134/S1061830911090038.

19. Variation of Magnetic Properties of Two-Layer Carbon-Steel Products under Tension /

E. S. Gorkunov, S. M. Zadvorkin, I. G. Emel'yanov, S. Yu. Mitropol'skaya // The Physics of Metals and Metallography. - 2007. - Vol. 103, no. 6. - P. 624-632. - DOI: 10.1134/S0031918X07060129.

20. Coercive Force of a Package of Steel Sheets with Diff erent Degrees of Magnetic Hardness / E. S. Gorkunov, A. M. Povolotskaya, V. G. Kuleev, V. K. Chistyakov, O. B. Korobka // Russian Journal of Nondestructive Testing. - 2002. - Vol. 38, no. 5. - P. 331-338. DOI: 10.1023/A:1020960918166.

21. Модель напряженно-деформированного состояния двухслойного стального изделия при одноосном растяжении / Э. С. Горкунов, И. Г. Емельянов, С. М. Задворкин, С. Ю. Митропольская // Металлы. - 2007. - № 1. - С. 78-82.

22. Гольдштейн М. И., Грачев С. В., Векслер Ю. Г. Специальные стали : учебник для вузов. 2-е изд., перераб. и доп. - М. : МИСИС, 1999. - 408 с.

23. Филиппов М. А., Литвинов В. С., Немировский Ю. Р. Стали с метастабильным аустенитом. - М. : Металлургия, 1988. - 255 с.

24. The Application of Magnetic Structural Phase Analysis for the Diagnostics of the State of a 08X18H10T Steel-C 3 Steel Composite Material and its Components that Were Subjected to Plastic Deformation / E. S. Gorkunov, S. M. Zadvorkin, E. A. Putilova, A. M. Povolotskaya, L. S. Goruleva, I. A. Veretennikova, I. S. Kamantsev // Russian Journal of Nondestructive Testing. - 2012. - Vol. 48, no. 6. - P. 346-356. - DOI: 10.1134/S1061830912060022.

25. Gorkunov E. S., Zadvorkin S. M., Putilova E. A. Magnetic estimation of stresses applied to a two-layer steel C(T)3-steel 08X18H10T composite material during elastoplastic deformation by uniaxial tension // Russian Journal of Nondestructive Testing. - 2012. - Vol. 48, no. 8. - P. 495-504. DOI: $10.1134 / \mathrm{S} 1061830912080050$. 